\title{
O crítico José Veríssimo: literatura, história e educação
}

\author{
Márcio Roberto Pereira* \\ Universidade Estadual de São Paulo \\ Assis, Brasil \\ Recebido em: 28/04/2019 \\ Aceito em: 05/06/2019
}

\begin{abstract}
Não existe literatura de que apenas há notícias nos repertórios bibliográficos ou quejandos livros de erudição e consulta. Uma literatura, e às modernas de após a imprensa me refiro, só existe pelas obras que vivem, pelo livro lido, de valor efetivo e permanente e não momentâneo e contingente. A literatura brasileira (como aliás sua mãe, a portuguesa) é uma literatura de livros na máxima parte mortos, e sobretudo de nomes, nomes em penca, insignificantes, sem alguma relação positiva com as obras. Estas, raríssimas são, até entre os letrados, os que ainda as versam. Não pode haver maior argumento da sua desvalia. José Fernando Veríssimo, História da literatura brasileira, 1916.
\end{abstract}

Resumo: Publicada em 1916 e escrita no decorrer da carreira de José Veríssimo, a História da literatura brasileira: de Bento Teixeira (1602) a Machado de Assis (1908) representa a confluência de todas as atividades do crítico paraense como intelectual. Assim sendo, o objetivo desse trabalho é fazer uma reflexão entre as tarefas de crítico e historiador literário e as de intérprete da nação brasileira, por meio da aproximação entre os diversos discursos que compõem a História, em especial literatura e educação. Ao propor a definição dessas duas linhas, observa-se que a obra de José Veríssimo possui uma organicidade e um apuramento de seus critérios de análise.

Palavras-chave: José Veríssimo. História da literatura brasileira. Crítica literária. Educação.

Abstract: Published in 1916 and written during José Veríssimo's career, the History of Brazilian Literature: from Bento Teixeira (1602) to Machado de Assis (1908) represents the confluence of all the activities of the critic from Pará as an intellectual. Thus, the objective of this work is to bring together the tasks of literary critic and historian and those of interpreter of the Brazilian nation, through the approximation between the various discourses that make up history, especially literature and education. In proposing the definition of these two lines, it is observed that the work of José Veríssimo has an organicity and a refinement of its analysis criteria.

Keywords: José Veríssimo. History of Brazilian Literature. Literary criticism. Education.

Zusammenfassung: Die 1916 veröffentlichte und während José Veríssimos Karriere geschriebene Geschichte der brasilianischen Literatur: von Bento Teixeira (1602) bis Machado de Assis (1908) stellt den Zusammenfluss aller Aktivitäten des Kritikers aus Pará als Intellektueller dar. So ist das Ziel dieser Arbeit ist es, eine Reflexion zwischen den Aufgaben der Kritik und Literaturhistoriker und denen der Dolmetscher der brasilianischen Nation, durch die Annäherung zwischen den verschiedenen Diskursen, die die Geschichte, insbesondere Literatur und Bildung. Bei dem Vorschlag, die Definition dieser beiden Linien, wird festgestellt, dass die Arbeit von José Veríssimo hat eine Organizität und eine Verfeinerung der Analyse Kriterien.

Schlüsselwörter: José Veríssimo. Geschichte der brasilianischen Literatur. Literaturkritik. Bildung. 


\title{
Introdução
}

Na introdução de sua História da literatura brasileira, José Veríssimo (18571916) afirma que tal obra é um remate de sua vida literária. Composta por dezenove capítulos e publicada em 1916, a História reúne todas as posições críticas que envolveram José Veríssimo na construção do pensamento cultural brasileiro e representa uma síntese de aproximadamente três décadas de exercício da crítica, na qual ele reorganiza e ratifica suas posições teóricas e históricas. Assim sendo, estabelece-se um lento processo de ruptura com uma crítica de caráter inteiramente cientificista, de cunho etnológico ou mesológico, que buscava a configuração de um cânone literário brasileiro centrado num “nacionalismo universal”. Segundo Wilson Martins (1957):

\begin{abstract}
A preocupação nacionalista o conduzia às leituras universais, pois somente estas poderiam fornecer-lhe os pontos de comparação de que necessitava, as leituras universais despertaram-lhe ou acentuaram-lhe a inclinação estética, da mesma forma porque esta última o projetava para aquelas; enfim; Veríssimo, dominado pelo ideal de uma literatura brasileira, não entendia nem o adjetivo nem no sentido político, nem no sentido sociológico, nem no sentido patriótico: ele queria, sim, uma literatura brasileira, mas que fosse, antes e acima de tudo, uma grande literatura. (MARTINS, 1957, p. 5)
\end{abstract}

Com esses objetivos, a História da literatura brasileira, de José Veríssimo, é dividida em duas partes, período colonial e período nacional, traçando um caminho que pode ser verificado no seguinte subtítulo da obra: "de Bento Teixeira (1602) a Machado de Assis (1908)”. Ao propor essa trajetória, o crítico descreve um lento processo de independência cultural que passa por diversas formas ao se pensar uma história literária. Não por acaso, Veríssimo publica sua História da literatura brasileira no ano de sua morte expondo ali o amadurecimento e a seleção de uma tradição literária que foi delineando-se, e consequentemente distanciando-se da matriz portuguesa, a partir do século XVII.

Escrita em 1912, a Introdução à História ratifica esse caminho ao propor uma leitura que amplia as fontes teóricas (a influência de teóricos franceses e portugueses deixa de ser exclusiva quando Veríssimo abre-se para a crítica americana, espanhola, inglesa, entre outras) para o entendimento da formação da 
literatura brasileira, aliado ao fato de se tomar a obra de Machado de Assis como ponto de referência não apenas nacional, mas universal. Para João Alexandre Barbosa, a História da literatura brasileira:

\begin{abstract}
Surgida sob o impacto poderoso que provocara no Brasil a difusão daquilo que ele mesmo (José Veríssimo) chamava de bando de idéias novas, sobretudo a partir dos anos 70 , isto é, os princípios do positivismo, do evolucionismo e do determinismo, não apenas buscava fazer a crítica de princípios românticos que informara a atividade crítico-histórica imediatamente anterior, mas fazia da história literária a expressão de uma interpretação de largo espectro da cultura no Brasil, a História de José Veríssimo já revelava o diálogo, sempre problemático para um homem de sua formação, em tudo semelhante à de Sílvio Romero, com os novos modelos de crítica, instaurados, como sempre acontece, a partir das próprias inovações literárias. (BARBOSA, 2002, p. 116)
\end{abstract}

Ao adotar o posicionamento de um crítico literário, que julga e determina valores, utilizando-se da historiografia como referência, não colocando-se como um historiador no sentido mais purista da palavra, José Veríssimo organiza um campo intelectual, convertendo a crítica literária num gênero que traduz, legitima e hierarquiza as obras literárias em fatores intrínsecos e extrínsecos ao seu campo intelectual de ação. Acompanha-se a trajetória da literatura brasileira em sintonia com os aspectos históricos, sociais, linguísticos, educacionais, entre outras linhas paralelas que se destacam na obra de Veríssimo.

Para José Veríssimo, portanto, a formação do leitor estava estreitamente relacionada ao método pelo qual o crítico literário - "guardião da tradição" seleciona aquelas obras mais importantes para a cultura nacional. Conforme o crítico, "a literatura, como arte literária é, como toda arte, proeminentemente expressão.” (VERÍSSIMO, 1936, p.133). Considerando-a como “expressão”, a literatura deve "representar" a emancipação das letras nacionais e, consequentemente, do leitor, principal alvo de Veríssimo. Destaca-se que sua participação como professor e crítico eram entremeadas com atividades como a de fundador e secretário da Academia Brasileira de Letras, o que determina sua incansável participação em diversas frentes de atuação. Somente com o Romantismo, o leitor nacional passa a tomar consciência de sua função para a 
formação de uma literatura que adquire qualidade através da sintonia entre obra, público e crítica. Segundo José Veríssimo:

\begin{abstract}
O nosso Romantismo foi a nossa emancipação literária, 1) dotando as nossas letras, até aí quase confinadas na poesia, com o teatro, a história literária, a crítica, os estudos filosóficos, as letras morais, o romance, a novela, o conto, enfim, todos os gêneros literários; 2) traduzindo fielmente os sentimentos e aspirações da nova nacionalidade, ainda vivamente abalada pelos sucessos da Independência, do Sete de Abril, das Regências e da Maioridade; 3) exprimindo tais sentimentos, e a alma nova que aqui se criava, não mais respeitosamente segundo o modelo castiço, porém segundo o nosso falar nativo. (VERÍSSIMO, 1936, p.133-4)
\end{abstract}

Dessa forma, a Introdução e os capítulos que compõem a História da literatura brasileira são escritos, modificados, cortados, ampliados e remodelados no decorrer de toda a carreira do crítico paraense. Isso se deve aos diversos espaços de atuação que perpassam a carreira de Veríssimo, não restringindo-se apenas ao jornal ou livros, mas promovendo uma atuação em espaços como a sala de aula, os conservatórios e bibliotecas, entre outros.

O capítulo 1, da História da Literatura Brasileira, por exemplo, foi escrito a partir do aproveitamento de ideias de dois principais artigos. O primeiro, e mais importante, intitula-se Sobre a formação da literatura brasileira e foi publicado na Kosmos: revista artística, científica e literária. Ano III - número 12. dezembro de 1906. O segundo intitula-se "A nossa evolução literária" - Conferência pronunciada na Biblioteca Nacional, em 26 de setembro de 1912. Publicado nos Anais da Biblioteca Nacional do Rio de Janeiro, vol. 35, 1913, Rio de Janeiro, 1916. Páginas 11 a 21”. Publicado também nos Últimos Estudos de Literatura Brasileira $7^{\mathrm{a}}$. Série, 1979. p. 43-57.

José Veríssimo sempre foi um crítico preocupado em traçar grandes panoramas para a literatura brasileira. No entanto, esse processo foi refinando-se no decorrer de sua carreira, seja quando tratava de movimentos literários, seja quando tratava de escritores de forma isolada. Uma característica, contudo, é marcante na História da literatura brasileira: o delineamento de ideias gerais com diversos nomes que, no decorrer do texto, vão afunilando-se num nome de maior representatividade. Isso acontece nos capítulos da História e ocorre, também, nos 
capítulos dedicados a individualidades literárias, sempre se destacando uma espécie de amadurecimento da obra ou do estilo do autor analisado.

Ao se cotejar os capítulos com os textos que serviram de base para compor a História da literatura brasileira, nota-se como esse processo se concretiza:

\section{Quadro 1: Cotejo entre as versões de José Veríssimo}

1- Não é, pois, de estranhar que em nenhum dos primeiros cronistas e noticiadores do Brasil, no primeiro e ainda no segundo século da colonização, mesmo quando já havia manifestações literárias, se não encontre a menor referência ou alusão a qualquer forma de atividade mental aqui, a existência de um livro, de um estudioso ou cousa que o valha. $\mathrm{O}$ padre Antonio Vieira, homem de letras como era, em toda a sua obra, abundante de notícias, referências e informes do Brasil do século XVII, apenas uma vez, acidental e vagamente lhe alude a literatura. Foi quando, escrevendo ao mordomo-mor do Reino, contou, jogando de vocábulo, que na Bahia, "sobre se tirarem as capas aos homens (por decisão de um novo governador) têm dito mil lindezas os poetas, sendo maior a novidade deste ano (1682) nestes engenhos do que nos de açúcar"

2- Entretanto no tempo de Vieira, a maior parte do século XVII, já no Brasil havia manifestações literárias no medíocre poema de Bento Teixeira (1601) e nos poemas e prosas ainda então inéditas mas que circulariam em cópias ou seriam conhecidas de ouvido, de seu próprio irmão Bernardo Vieira Ravasco, do padre Antonio de Sá, pregador, de Eusébio de Matos e de seu irmão Gregório de Matos, o famoso satírico, de Botelho de Oliveira, sem falar nos que incógnitos escreviam relações, notícias e crônicas da terra, um Gabriel Soares (1587), um Frei Vicente do Salvador, cuja obra é de 1627, o ignorado autor dos Diálogos das grandezas do Brasil e outros de que há notícia.

3- Não trouxeram, pois, os portugueses para o Brasil algo do movimento literário que ia àquela data em sua pátria. Mas evidentemente trouxeram a capacidade literária já ali desde o século XIII pelo menos revelada pela sua gente e que naquele em que aqui se começaram a estabelecer atingia ao seu apogeu. As suas primeiras preocupações de ordem espiritual, que possamos verificar, produziram-se quase meio século após o descobrimento com a chegada dos primeiros jesuítas em 1549, e sob a influência destes.
1- Em nenhum dos primitivos cronistas e narradores das coisas do Brasil, no primeiro e ainda na maior parte do segundo século da colonização, se encontra mínima referência, ou sequer vaga alusão, a alguma manifestação, por insignificante que fosse, de qualquer forma de vida espiritual aqui, a existência de um livro, de um estudioso, ou coisa que valha. $\mathrm{O}$ padre Antônio Vieira, um homem de letras, em toda a sua vasta obra, abundante de notícias, referências, alusões ao Brasil nunca deixou perceber que houvesse aqui alguma, mesmo apagada, preocupação intelectual.

"Sobre a formação da literatura brasileira". Kosmos: revista artística, científica e literária. Ano III, número 12. Dezembro de 1906.

2- No tempo de Vieira, segunda metade do século XVII, já no Brasil havia manifestações literárias no medíocre poema de Bento Teixeira (1601) e nos poemas e prosas, ainda não inéditos, mas que circulariam em cópias ou seriam conhecidos de tradição, de Bernardo Vieira Ravasco, irmão do famoso padre, do padre Antonio de Sá, pregador, de Eusébio de Matos, o famoso satírico, de Manoel Botelho de Oliveira, sem falar nos que, desconhecidos, modestos, escondidos, escreviam relações e memórias da terra, um Gabriel Soares (1540), um Fr. Vicente do Salvador (1564-163...), um Padre Francisco de Souza (1628-1713), o autor ignorado do Diálogos das grandezas do Brasil (...)

"Sobre a formação da literatura brasileira". Kosmos: revista artística, científica e literária. Ano III, número 12. Dezembro de 1906.

3- Os portugueses não trouxeram, pois, para o Brasil nada do movimento literário da sua pátria. Mas evidentemente trouxeram a capacidade literária revelada por sua gente.

"Sobre a formação da literatura brasileira". Kosmos: revista artística, científica e literária. Ano III, número 12. Dezembro de 1906.

As escolas, de ler, escrever e contar, gramática latina, casos de consciência, doutrina cristã e mais tarde retórica e filosofia escolástica que aqueles 
As escolas de ler, escrever e contar, gramática latina, casos de consciência, doutrina cristã e mais tarde retórica e filosofia escolástica, logo abertas por esses padres nos seus "colégios", imediatamente a sua chegada fundados, foram a fonte donde promanou, no primeiro século, toda a cultura brasileira e com ela os primeiros atentos da literatura. padres logo abriram nos seus "colégios" foram a fonte donde derivou, no primeiro século, toda a cultura brasileira, e com ela a literatura.

"Sobre a formação da literatura brasileira". Kosmos: revista artística, científica e literária. Ano III, número 12. Dezembro de 1906.

Fonte: elaborado pelo autor

Os fragmentos da coluna esquerda, que compõem o capítulo I, da História da literatura brasileira, intitulado "A primitiva sociedade colonial”, mostram o processo de montagem de panoramas que traçam a "evolução" da sociedade brasileira em sintonia com o aparecimento de escritores com um melhor aparato estético. É importante observar que, ao preparar e refinar seus textos em jornais, revistas, palestras, conferências, etc, o crítico também modula sua obra final.

José Veríssimo sempre se preocupou em traçar panoramas para a literatura brasileira. Ao escrever ensaios panorâmicos, o crítico pretendia "fornecer aos que porventura se interessam pelo assunto uma noção tão exata e tão clara quanto em meu poder estiver, do nosso progresso literário, correlacionado com a nossa evolução nacional.” (VERÍSSIMO, 1916, p. 23).

Entre “avanço literário" e "evolução nacional” percebe-se que há um descompasso porque literariamente existe uma linha progressiva, de Bento Teixeira a Machado de Assis, porém, a sociedade e, consequentemente, a educação nacional não conseguem adquirir o desenvolvimento das nações europeias, nem mesmo o "desenvolvimento" adquirido pela literatura nacional. É nesse "descompasso" que se constrói a História da literatura brasileira, mesclando capítulos panorâmicos com capítulos individuais. Nota-se, também, a composição da obra de José Veríssimo, como é possível observar no cotejo dos fragmentos acima, que o geral e o particular sempre se equilibram no contraponto entre literatura e sociedade, entre escritor e movimento literário e, por fim, entre teorias estrangeiras e interpretação da realidade local. 
Assim sendo, a literatura brasileira, para José Veríssimo, mesmo possuindo uma representação universal na obra de Machado de Assis, contrapõe-se a uma sociedade que continua na ignorância. "Para reformar e restaurar um povo, escreve Veríssimo - um só meio se conhece, quando não infalível, certo e seguro, é a educação, no mais largo sentido, na mais alevantada acepção desta palavra.” (VERÍSSIMO,1906, p. 52).

Conforme João Alexandre Barbosa:

Dizendo de outro modo, não haveria espaço mais apropriado do que o da história literária para servir como ponto de fusão entre os critérios de que se embebera em sua formação (etnologia, nacionalismo) e aqueles propostos pela revisão a que submetera os anteriores por força das novas influências e do próprio evolver, como já se viu, da sociedade brasileira que o crítico passara a experimentar a partir de 1891. (BARBOSA, 1974, p. 196)

Esse "ponto de fusão", destacado por João Alexandre Barbosa, é responsável pela constante remodelação das ideias e perspectivas de José Veríssimo que, na História da literatura brasileira ganha seu formato mais orgânico. Para isso é muito importante destacar a Introdução que, conforme explicitado acima, foi escrita em 1912. Mesmo possuindo um hiato temporal até sua inserção na História, em 1916, observa-se que o projeto de Veríssimo amadurece pela constante exposição e confronto de ideias, polêmicas e divulgação constante nas páginas de jornais e revistas. Na compreensão de Heron de Alencar:

E seu ler é um ler ativo, de quem procura por exigência prática, nunca por diletantismo; e seu trabalho é um constante criar e recriar de instrumentos para melhor conhecer o objeto de seu estudo, jamais a ostentação de um saber puramente retórico, quase nunca a expressão de entusiasmos irrefletidos por novidades estéticas, filosóficas ou literárias. (1963, p. XXI)

Seja por "fusão" ou por uma intensa atividade, José Veríssimo redefine e remodela seus textos, com a intenção de construir uma história da literatura brasileira, a partir de seu próprio entendimento sobre o conceito de literatura. Em 1889, no Pará, ao publicar Estudos brasileiros (1877-1885) e analisar todo o 
contexto de formação, divulgação e recepção da obra literária em seus diversos contextos, o crítico entende que a literatura é "sinônimo do conjunto de todas as manifestações de ordem intelectual trazidas pela escrita no domínio da ciência, no domínio da arte ou no domínio das letras" (VERÍSSIMO, 1899, p. 18). Tal posição, vai sendo ratificada e reelaborada no decorrer da carreira do crítico, em especial quando este muda-se para o Rio de Janeiro, tornando-se mais atuante no contexto cultural do Brasil.

Em sua obra Que é literatura? e outros escritos, publicada no Rio de Janeiro em 1907, Veríssimo amplia seu horizonte de referências teóricas a partir de críticos como o português Moniz Barreto (1865-1896), o norte-americano C.T. Winchester (1847-1920) e o francês Brunetière (1849-1906), esboçando uma nova definição sobre arte literária:

\footnotetext{
Várias são as acepções do termo literatura: conjunto da produção intelectual humana escrita; conjunto de obras especialmente literárias; conjunto (e esse sentido, creio, nos veio da Alemanha) de obras sobre um dado assunto, ao que chamamos mais vernaculamente bibliografia de um assunto ou matéria; boas letras; e, além de outros derivados secundários, um ramo especial daquela produção, uma variedade da Arte, a arte literária. (VERÍSSIMO, 1907, p. 14)
}

No lento processo de adaptação das matrizes teóricas vindas da Europa e Estados Unidos, José Veríssimo constrói seu conceito de literatura que, por sua vez servirá de ponto de referência para entender e justificar a ideia de uma história da literatura brasileira que inicia-se em 1602, por que já possui aquilo que Antonio Candido definirá posteriormente como "sistema literário", finalizando em um ponto máximo de referência, até aquele momento, com a obra de Machado de Assis. Ademais, nota-se que o papel do crítico como um formador de leitores aproxima José Veríssimo da plena inserção da literatura no contexto educacional brasileiro. Tal refinamento terá como resultado a seguinte definição de literatura:

Somente o escrito com o propósito ou a intuição dessa arte, isto é, com os artifícios de invenção e de composição que a constituem, é, a meu ver, literatura. Assim pensando, quiçá erradamente, pois não me presumo de infalível, sistematicamente excluo da história da literatura brasileira quanto a esta luz se não deva considerar literatura. Esta é 
neste livro sinônimo de boas ou belas-letras, conforme a vernácula noção clássica. Nem se me dá da pseudonovidade germânica que no vocábulo literatura compreende tudo o que se escreve num país, poesia lírica e economia política, romance e direito público, teatro e artigos de jornal e até o que se não escreve, discursos parlamentares, cantigas e histórias populares, enfim autores e obras de todo o gênero. (VERÍSSIMO, 1916, p.10)

A definição acima reforça o caráter revisionista proposto por José Veríssimo ao situar a literatura em diversos contextos - arte, educação, sociedade, história, entre muitos outros - pluralizando os contextos, mas explicitando a natureza independente do aspecto literário. Nesse sentido, o posicionamento do crítico literário amplia-se para uma nova configuração: a do intelectual. Ou seja, aquele que congrega todos os aspectos que permeiam, orbitam e compõem a atividade literária. O escritor seria, dessa forma, parte de um macrocosmo de atividades que teriam por objetivo aquilo que Antonio Candido definia como "processo de humanização"1.

Em outras palavras, a permanência da tradição literária no presente caracteriza-se por uma percepção dinâmica que transcende o valor estético. Nas palavras de Veríssimo:

\begin{abstract}
A história da literatura brasileira é, no meu conceito, a história do que da nossa atividade literária sobrevive na nossa memória coletiva de nação. Como não cabem nela os nomes que não lograram viver além do seu tempo também não cabem nomes que por mais ilustres que regionalmente sejam não conseguiram, ultrapassando as raias das suas províncias, fazerem-se nacionais. Este conceito presidiu à redação desta história, embora com a largueza que as condições peculiares à nossa evolução literária impunham. (1916, p. 13)
\end{abstract}

A constante percepção de encarar a crítica, ou o trabalho intelectual, como sendo responsável pela formação de uma “memória coletiva de nação” levou José Veríssimo a estabelecer contrapontos entre a profissionalização do escritor, a qualidade das obras literárias, a formação do cânone nacional, o papel da crítica como mediadora eficaz do processo de formação de leitores. O crítico paraense

\footnotetext{
1 Segundo CANDIDO (2004, p.180) "o processo que confirma no homem aqueles traços que reputamos essenciais, como o exercício da reflexão, a aquisição do saber, a boa disposição para com o próximo, o afinamento das emoções, a capacidade de penetrar nos problemas da vida, o senso da beleza, a percepção da complexidade do mundo e dos seres, o cultivo do humor."
} 
buscava permanente cruzamento da atividade literária com a educação nacional, por isso atuava de forma combatente nos jornais, revistas e espaços de cultura em sua época. Conforme bem define João Alexandre Barbosa:

\begin{abstract}
As atividades educacionais de José Veríssimo, portanto, podem servir para mais caracterizar as suas vinculações com toda uma geração convencida da urgência de pôr o Brasil na corrente de reflexões e métodos novos, atraída, por isso, pelos modelos educacionais que incluíam não somente uma parcela muito maior das populações urbanas, como ainda exigiam maior responsabilidade dos governantes. (BARBOSA, 1996, p. 198)
\end{abstract}

Apesar desse prolongamento da condição colonial em que vivia grande parte da população, a sociedade brasileira se desenvolvia a partir de um modelo centrado nas atividades urbano-comerciais em que o analfabetismo constituía um entrave ao crescimento do país, considerando que o domínio da leitura e da escrita são instrumentos necessários para a inclusão de grande parte da população no contexto social.

Alguns intelectuais defendiam o combate ao analfabetismo como forma de valorização do nacionalismo e da formação patriótica de um país que ainda era fragmentado politicamente. Partindo do pensamento de Theodor Adorno "quanto mais a educação procura se fechar ao seu condicionamento social, tanto mais ela se converte em mera presa da situação social existente" (ADORNO, 2000, p.11), os bacharéis do século XIX visualizavam a criação de uma ideologia que indicava a educação como fim de todos os males sociais, procurando solidificar uma estratificação social que integrasse o indivíduo à sociedade através da recriação, via educação, de relações sociais entre estruturas desiguais. Segundo José Veríssimo: "pessimamente organizada, a instrução pública no Brasil não procurou jamais ter uma função na integração do espírito nacional. A escola viveu sempre acaso mais isolada pelo espírito que pelo espaço e topografia.” (VERÍSSIMO, 1907, p.58). Isso se deve porque o ensino sempre esteve muito ligado ao Estado, não existindo uma preocupação, por parte dos intelectuais, com os aspectos pedagógicos e a formação da nação. Somente após a República, os bacharéis, excluídos do poder, começam a acreditar na educação como uma 
forma de diminuir o atraso em relação ao mundo europeu. Ao se observar o contraponto entre cultura europeia e brasileira, Veríssimo define que:

\begin{abstract}
Para se compreender perfeitamente o espírito de um povo é necessário estudar bem os diferentes elementos que o compõem. É sobre esse critério que assentamos o nosso modo de pensar de que é do estudo bem feito dos elementos étnicos e históricos de que se compõe o Brasil, da compreensão perfeita do nosso estado atual, de nossa índole, de nossas crenças, de nossos costumes e aspirações que poderá sair uma literatura que se passa a chamar conscientemente brasileira, à qual ficará reservado o glorioso destino de fazer entrar este país, pela forte reação de que falamos atrás, numa nova via de verdadeira civilização e progresso. (VERÍSSIMO, 1977, p.162)
\end{abstract}

O exemplo do limitado acesso à educação, por parte da maioria da população brasileira, pode ser apontado através da sinopse do recenseamento realizado em setembro de 1920:

Tabela 1: Recenseamento 1920

População brasileira

\begin{tabular}{|c|c|c|c|}
\hline $\begin{array}{c}\text { População } \\
\text { brasileira }\end{array}$ & $\begin{array}{c}\text { Sabem ler e escrever } \\
\text { \% sobre o total de } \\
\text { habitantes } \\
\text { considerados. }\end{array}$ & $\begin{array}{c}\text { Não sabem } \\
\text { Ler e escrever }\end{array}$ & $\begin{array}{c}\text { Total de } \\
\text { habitantes }\end{array}$ \\
\hline \multirow{2}{*}{1872} & 1.564 .481 & 8.365 .997 & 9.930 .478 \\
\hline \multirow{2}{*}{1890} & $16 \%$ & $84 \%$ & - \\
\cline { 2 - 4 } & 2.120 .559 & 12.213 .356 & 14.333 .915 \\
\hline \multirow{2}{*}{1900} & $15 \%$ & $85 \%$ & - \\
\hline \multirow{2}{*}{1920} & 4.448 .681 & 12.989 .753 & 17.438 .434 \\
\cline { 2 - 4 } & $25 \%$ & $75 \%$ & 30.635 .605 \\
\hline
\end{tabular}

Fonte: : Sinopse do Recenseamento realizado em 1 de setembro de 1920, População do Brasil, "Coeficientes da população dos Estados do Brasil em 1872, 1890 e 1920 segundo o grau de instrução e a idade". Rio de Janeiro: Imprensa Estatística, s/d.

A tabela acima, de acordo com a Sinopse do Recenseamento realizado em setembro de 1920, intitulado A população do Brasil: coeficientes da população dos Estados do Brasil em 1872, 1890 e 1920 conforme o grau de instrução e idade. (s/d, p. 26-7), indica que no século XIX, e inícios do século XX, a alfabetização era privilégio de poucos e a prática da leitura, dessa forma, ficava restrita a uma elite que norteava o padrão cultural da nação. Além do acesso limitado à educação, o 
consumo de outros meios de cultura, como jornais, revistas, livros, acessos a bibliotecas também ficavam circunscritos a uma minoria que também delineava os padrões culturais e artísticos. É importante observar que as porcentagens entre os que sabem ler e escrever quase não se alteraram no decorrer dos anos, mostrando a ausência de políticas públicas para a educação nacional.

Dessa forma, a importância de intelectuais que repensassem a literatura e as artes em geral num contexto mais amplo de nação, migrava para o espaço dos jornais, revistas e, posteriormente, para o livro as discussões sobre o papel da educação e da cultura no desenvolvimento da sociedade. Nota-se, portanto, que a construção da História da literatura de brasileira, de José Veríssimo, não é apenas a busca por unificar e acompanhar a trajetória de autores e obras que ratificavam a existência de uma nação imaginada literariamente mas denota um importante projeto de desenvolvimento de um método crítico que espalha-se por diversas instâncias, assim como o papel do intelectual. No pensamento de Antonio Candido:

\footnotetext{
Se fosse possível estabelecer uma lei de evolução de nossa vida espiritual, poderíamos talvez dizer que toda ela se rege pela dialética do localismo e do cosmopolitismo, manifestada pelos modos mais diversos. Ora a afirmação premeditada e por vezes violenta do nacionalismo literário, com veleidades de criar até uma língua diversa; ora o declarado conformismo, a imitação consciente dos padrões europeus. (CANDIDO, 2000, p. 101)
}

Essa dialética que perpassa a escola, as universidades, as bibliotecas, os jornais e revistas, a Academia Brasileira de Letras, os conservatórios de música e teatro, as histórias da literatura, entre diversas outras instâncias, dinamiza a discussão sobre a necessidade de novas relações entre o Brasil e outras nações. Assim sendo, a História representa uma espécie de distanciamento do meio e do momento tornando-se dissonante frente a uma sociedade que possuía uma crença nas reformas sociais e políticas da República, mas, ao mesmo tempo, convivia com a continuidade de um modelo de exploração colonial.

Consciente do importante papel da literatura no processo de desenvolvimento da sociedade brasileira, José Veríssimo entende a ideia de 
nacionalismo além do contexto de uma nação imaginada, mas, por outro lado, inserida no contexto do Brasil:

O iletrado brasileiro - ainda a pouco $84 \%$ da população - nada encontrou que impressionando seus sentidos lhe falasse da pátria e a seu modo fosse também um fator de sua educação. Não há museus, não há monumentos, não há festas nacionais. O que frequentou a escola onde lhe não fizeram conhecer e amar, desadorando a leitura e o estudo, não procurou fazer-se a si próprio uma educação patriótica. Esta mesma boa vontade ser-lhe-ia, aliás, difícil realizar, pela falta de elementos indispensáveis. Porque, em virtude mesmo desta indiferença pelas coisas nacionais, conforme vou aqui apontando, de modo algum combatida pela educação pública, é paupérrima a mesma literatura nacionalista. (VERÍSSIMO, 1907, p. 165)

As diversas atividades de José Veríssimo redundam na busca por uma história da literatura que acompanhasse não apenas o individual aprimoramento da qualidade estética dos escritores que compõem o cânone proposto na História da literatura brasileira. O crítico busca a implementação de uma educação, não apenas centrada nas questões nacionais, mas também em temas e problemas universais. Nesse sentido, a obra de Veríssimo representa a imagem de um nacionalismo universal, que necessitava de mediadores e espaços de interação capazes de promover o "esclarecimento" do indivíduo e da nação.

\section{Referências}

ADORNO, T. W. Educação e emancipação. $2^{\mathrm{a}}$. edição. Tradução de Wolfgang Leo Maar. Rio de Janeiro: Paz e Terra, 2000.

ALENCAR, Heron de. Sobre José Veríssimo. In: VERÍSSIMO, J. História da literatura brasileira: de Bento Teixeira (1601) a Machado de Assis (1908). 4a. edição. Brasília: Editora da Universidade de Brasília, 1963.

BARBOSA, João Alexandre. A tradição do impasse: linguagem da crítica e crítica da linguagem em José Veríssimo. São Paulo: Ática, 1974 A biblioteca imaginária. São Paulo: Ateliê Editorial, 1996. 
A História da literatura brasileira de José Veríssimo. In: BARBOSA, J. A. Alguma crítica. São Paulo: Ateliê Editorial, 2002.

CANDIDO, A. O direito à literatura. In: Vários escritos. $4^{\underline{a}}$ ed. São Paulo/Rio de Janeiro: Duas Cidades/Ouro sobre azul, 2004, p. 169-191. . Literatura e cultura de 1900 a 1945. In: . Literatura e sociedade.

8a. edição. São Paulo: T. A Queiroz; Publifolha, 2000.

MARTINS, W. O crítico José Veríssimo. In: O Estado de S. Paulo (Suplemento literário). São Paulo, 14 de maio de 1957.

Sinopse do Recenseamento realizado em 1 de setembro de 1920, População do Brasil, "Coeficientes da população dos Estados do Brasil em 1872, 1890 e 1920 segundo o grau de instrução e a idade". Rio de Janeiro: Imprensa Estatística, s/d.

PEREIRA, M. R. José Veríssimo: crítica, história e educação. Orientador: Dr. Luiz Roberto Velloso Cairo. Tese (Programa de Pós-graduação em Letras) - Faculdade de Ciências e Letras de Assis - Universidade Estadual Paulista, UNESP, FCL, Assis-SP, 2003. $349 \mathrm{f}$.

VENTURA, R. Estilo tropical; história cultural e polêmicas literárias no Brasil 1870-1914. $2^{\underline{a}}$ reimpressão. São Paulo: Companhia das Letras, 1991.

VERÍSSIMO, J. História da literatura brasileira: de Bento Teixeira (1601) a Machado de Assis (1908). $1^{\circ}$ milheiro. Rio de Janeiro: Livraria Francisco Alves \& Cia, 1916.

A educação nacional. Rio de Janeiro: Francisco Alves, 1906.

Literatura brasileira. In: VERÍSSIMO, J. Letras e literatos: estudinhos críticos da nossa literatura do dia. Rio de Janeiro: José Olympio, 1936.

Estudos brasileiros (1877-1885). Pará: Tavares Cardoso \& C, 1889.

Que é literatura? e outros escritos. Rio de Janeiro: Garnier, 1907.

. "Sobre a formação da literatura brasileira". Kosmos: revista artística, científica e literária. Ano III, número 12. Dezembro de 1906.

José Veríssimo: teoria crítica e história literária. Seleção e apresentação de João Alexandre Barbosa. Rio de Janeiro: Livros Técnicos e Científicos; São Paulo: Edusp, 1977. 
PEREIRA, MÁRCIO ROBERTO.

* Professor na Unesp (Assis) na área de Literatura Portuguesa. Pós-doutorado em Letras pela Universidade Estadual Paulista Júlio de Mesquita Filho- UNESP (Araraquara).

Doutor em LETRAS pela UNESP (Assis). 